This item was submitted to Loughborough's Research Repository by the author.

Items in Figshare are protected by copyright, with all rights reserved, unless otherwise indicated.

\title{
Third party interventions in coach-athlete conflict: can sport psychology practitioners offer the necessary support?
}

PLEASE CITE THE PUBLISHED VERSION

https://doi.org/10.1080/10413200.2020.1723737

\section{PUBLISHER}

Informa UK Limited, trading as Taylor \& Francis Group

\section{VERSION}

AM (Accepted Manuscript)

\section{PUBLISHER STATEMENT}

This is an Accepted Manuscript of an article published by Taylor \& Francis in Journal of Applied Sport Psychology on 5 Feb 2020, available online: http://www.tandfonline.com/10.1080/10413200.2020.1723737.

\section{LICENCE}

CC BY-NC-ND 4.0

\section{REPOSITORY RECORD}

Wachsmuth, Svenja, Sophia Jowett, and Chris Harwood. 2020. "Third Party Interventions in Coach-athlete Conflict: Can Sport Psychology Practitioners Offer the Necessary Support?”. Loughborough University. https://hdl.handle.net/2134/13607552.v1. 
Running head: THIRD PARTY INTERVENTIONS IN COACH-ATHLETE CONFLICT

Third party interventions in coach-athlete conflict: Can sport psychology practitioners offer the necessary support?

3 The relationship athletes develop with their coaches is instrumental for improved sport

4 performances and wellbeing (Jowett \& Shanmugam, 2016). Sport psychologists have been

5 encouraged to facilitate the development of effective coach-athlete relationships and may also

6 play a vital part in dealing with disruptions, such as interpersonal conflict. With this in mind,

7 the present study aimed to explore sport psychologists' roles in preventing and managing

8 coach-athlete conflict, as well as to examine potential challenges in doing so. Data were

9 collected via sixteen semi-structured interviews with experienced sport psychology

practitioners. A thematic analysis resulted in two overarching themes. The first theme encapsulated roles of sport psychology practitioners in managing coach-athlete conflict. The six identified subthemes included such roles as educating sport participants, facilitating dyadic interactions, or protecting individual conflict parties. The second overarching theme covered challenges perceived by sport psychology practitioners when providing support to coaches and athletes, the five subthemes included, for example, environmental and professional concerns. Based on this study, practical recommendations for the education of sport psychologists are drawn. These may include training in conflict prevention, mediation or even organizational change. Applied sport psychologists should furthermore be better prepared to cope with and manage power differences between themselves and others as well as between the various members of sport organizations (e.g., coaches, athletes, manager). Key words: Conflict management, communication, mediation, coaching, ethical practice

\section{Lay summary}

The relationship between coaches and athletes is crucial for sport performance and individual wellbeing. Thus, the presented study explored how sport psychology practitioners may facilitate this relationship during times of interpersonal difficulties and conflict by providing information, practicing interpersonal skills and mediating between conflict partners. 
Running head: THIRD PARTY INTERVENTIONS IN COACH-ATHLETE CONFLICT Third party interventions in coach-athlete conflict: Can sport psychology practitioners offer the necessary support?

$$
\text { Though sport psychologists are often hired to focus on performance-enhancement }
$$

through mental skills training (e.g., Wrisberg, Loberg, Simpson, Withycombe, \& Reed, 2010; Zakrajsek, Steinfeldt, Bodey, Martin, \& Zizzi, 2013), their remit can also cover a wider range of roles and responsibilities within diverse sport settings. Their work may, for example, target athletes' abilities to cope with injury and rehabilitation, to overcome competitive anxiety and withstand performance pressure, or to manage stress in general; it may also include life skills training more broadly (e.g., time management, goal setting). Additionally, sport psychologists have been suggested to offer pastoral care for athletes as well as to ensure sport participants' overall wellbeing (e.g., Cook \& Fletcher, 2017; Haberl \& Peterson, 2006; Wrisberg et al., 2010; Zakrajsek et al., 2013). Moreover, Cook and Fletcher (2017) emphasized elite coaches' desire to work closely with sport psychologists to support their management of personal demands within performance environments, as well as to synchronize coaches and staff members' messages communicated to performers. Thus, while coaches were concerned that sport psychologists potentially undermined their authority and presented a threat to coachathlete relationships, they also recognized sport psychologists' potential to establish a common vision and effective working relationships by coordinating communicative processes within an organization (Cook \& Fletcher, 2017). Overall, these findings align with the overarching tasks sport psychologists have been given in regards to shaping interpersonal processes, such as enhancing communication skills, increasing coaching effectiveness through leadership training, or promoting intra-team/ -organization relationships via teambuilding and conflict management (e.g., Haberl \& Peterson, 2006; Langan, Blake, \& Londsdale, 2013; Rhind \& Jowett, 2012; Vealey, 2017; Vella, Oades, \& Crowe, 2010; Zakrajsek et al., 2013). The importance of effective conflict management in the pursuit of close, trusting and collaborative sport relationships has been highlighted in recent research (e.g., Rhind \& Jowett, 
2012; Vealey, 2017; Wachsmuth, Jowett, \& Harwood, 2017). Within sports coaching and psychology, the topic of conflict has recently received some focused attention. Aligning with Barki and Hartwick's (2004) multidimensional conceptualization, interpersonal conflict has been defined as "a situation in which relationship partners perceive a disagreement $[\ldots]$ that is manifested through negative cognitive, affective, and behavioural reactions" (Wachsmuth et al., 2017; p.89). While conflict has generally been considered a dysfunctional process, recent studies on conflict in sports show that effective conflict management may help to negotiate potentially negative outcomes (e.g., stress reeducation, negative emotions) and even facilitate positive consequences (e.g., Vealey, 2017; Wachsmuth, Jowett, \& Harwood, 2018). For instance, a constructive approach to conflict marked by open communication, mutual understanding and willingness to find acceptable solutions for both sides, may enable athletes and coaches to form even closer working partnerships through the re-alignment of expectations, values and goals. However, given the environmental challenges within high performance settings (e.g., high pressure, hierarchical structures) as well as individuals' personal characteristics in regards to, for example, maturity and skill level, effective conflict management is not an easy endeavor. Hence, sport participants reportedly turned to third parties to seek support through these challenging times (e.g., Holt, Knight, \& Zukiwski, 2012; Vealey, 2017). In addition to family and friends, who may provide a safe space to vent frustration and seek emotional support sport psychologists can promote conflict prevention and management within sport relationships by offering advice, instilling accountability, or facilitating the conflict resolution process itself (Vealey, 2017; Wachsmuth et al., 2018). While there is some empirical evidence on team-focused interventions aiming at promoting positive athlete-athlete interactions (e.g., team building, mutual disclosure, conflict management; Holt et al., 2012; Martin, Carron, \& Burke, 2009; Vealey, 2017), limited information is available on how sport psychologists may support coaches and athletes in their efforts to form effective relationships and dealing with crises, such as conflict, 
misunderstandings or incompatibility. Yet, the coach-athlete relationship is understood to be vital to sport performance as well as for the overall development and wellbeing of athletes (Jowett \& Shanmugam, 2016) and therefore, its effectiveness and quality should be a major concern for sport organizations.

Vealey’s (2017) case study illustrated an applied example within which sport psychology consultants approached conflict management in sport teams and coach-athlete relationships by improving communication, fostering mutual disclosure and instilling a value-driven sporting culture. As communication provides an important medium for improving the quality of interpersonal relationships, the strategies outlined within the COMPASS model (Rhind \& Jowett, 2010) may provide a theoretical basis for building interventions that aim to promote more effective coach-athlete interaction. Within this model, seven communicative strategies are outlined which are thought to facilitate closeness, commitment and collaboration between coaches and athletes. Furthermore, Rhind and Jowett (2012) encouraged sport psychologists to "think dyadically" (p. 234) and offered advice on how to utilize these COMPASS strategies within their applied work. They explained that by enhancing open channels of communication and honesty as well as providing support, offering assurance and highlighting the expectations while outlining the consequences if expectations are not fulfilled, instances of conflict may not occur or can be resolved quicker if they do occur. Acknowledging that conflict may also occur within well-functioning coach-athlete relationships, it was further recommended to focus on the roots of disagreements rather than "treating the symptoms" (p. 236), and to support relationship members to communicate openly in an effort to identify mutually acceptable solutions to problems, as well as to review and revise adopted solutions over time. As such Rhind and Jowett (2012) highlighted sport psychologists' responsibility to help prevent and manage coach-athlete conflict. However, while these suggestions seem plausible and are supported by empirical research conducted on the coach-athlete relationship, they may not reflect the professional experiences of sport psychology practitioners. 
Running head: THIRD PARTY INTERVENTIONS IN COACH-ATHLETE CONFLICT

In contrast to the dearth of research that examines the role of sport psychology

106

107

108

109

110

111

112

113

114

115

116

117

118

practitioners in situations where coaches and athletes deal with challenge and conflict, ample literature exists on conflict management and resolution within other domains (e.g., business, psychotherapy). Thus, a wide range of approaches has been forwarded to successfully negotiate conflict within interpersonal relationships aiming at either directly solving the issue at hand or improving the relationship in general to promote long-term collaboration (Fisher, 2001); these approaches include traditional mediation, informal third party consultations or conciliation, and conflict resolution training (e.g., Fisher, 2001; Kressel, 2014). Of these, mediation has received the greatest research attention and is considered one of the most effective methods for managing moderate to high intensity conflict (Kressel, 2014). It is understood to be a rather formal, task-oriented process often utilized in professional settings. Besides mediation, relationship-oriented approaches such as conciliation or third party consultations have been recommended for conflicts of lower intensity (Fisher, 2001). These may be described as "informal communicative links" (Fisher, 2001; p. 11) aiming at reducing friction and increasing rapport between conflict parties. Overall, third party interventions seem to facilitate conflict resolution and additionally buffer negative conflict-induced consequences (e.g., Giebels \& Janssen, 2005). Being aware of established third party interventions in non-sport settings, research is warranted investigating whether and how these approaches inform the conflict management practice within sport.

In conclusion, few recommendations have been made in regards to sport psychologists' roles and possibilities to facilitate coach-athlete interactions and promote high quality working relationships, as well as to intervene in conflicts among athletes (e.g., Holt et al., 2012; Vealey, 2017; Wachsmuth et al., 2017). While the conflict management strategies proposed within the sport psychology literature seem to be similar to established practices in other settings, they are neither substantiated by empirical research nor described with enough precision to allow transfer into sport psychologists' own practices. Concerns may also arise 
131 about the overall contextual circumstances impeding sport psychologists' opportunities to

132 support coaches and athletes in conflict; for example, in regards to psychologists' general

133 roles and responsibilities within sport organizations. Thus, the current study aimed to, on one

134 hand, explore sport psychologists' roles in and approaches to managing coach-athlete conflict, 135 and, on the other hand, to examine barriers encountered by sport psychologists when working 136 with coach-athlete dyads in conflict.

\section{Methodology}

The present study was approached from a pragmatic philosophical standpoint which

139 describes the construction of knowledge (i.e., warranted assertions) through competent

140 inquiry by the functionality of individuals' actions within a given context (Dewey, 1922).

141 Thus, truth and knowledge are not external entities that can be discovered but rather represent

142 practical beliefs about the usefulness of warranted assertions which is ultimately formed

143 through social interactions. Drawing on the experiences of sport psychology practitioners as a

144 community engaged in high-performance sport (i.e., context), the current study explored

145 individuals' practical knowledge as it relates to conflict prevention and management (i.e.,

146 action) to identify functional actions which may in future be adopted and further improved by

147 practitioners working within such settings. As research underpinned by pragmatism may be

148 expected to provide immediate real-world impact, the current study's quality may not only be

149 evaluated based on methodological rigor but also by the applicability and additional benefit of

150 these findings to sport psychology practice. While the study does not aim to forward "rules"

151 for conflict management within sports in general, practitioners working in performance

152 settings are provided with information to which they can contrast their personal experiences.

153 This information may facilitate reflective practice and expand personal resources in terms of

154 specific conflict management strategies while considering specific environmental barriers.

155 Moreover, by shedding light on community practices and experienced challenges as well as

156 by pointing out alternative behaviors, the accumulated experiences and knowledge of 
practitioners can help to shape and transform future conflict-related practices within

158 performance sport.

Participants. A purposeful sample consisting of sixteen sport psychology

practitioners (SPP) working within the German $\left(n=9 ; M_{\text {age }}=45,56\right.$ years; 7 male, 2 female) and British ( $n=7 ; M_{a g e}=44,71$ years; 6 male, 1 female) sport system was recruited for this study. While participants were chosen from both countries for mainly practical reasons (e.g., accessibility), this decision can be justified considering the well-developed sports systems in Germany and the UK as well as the integration of sport psychology services on a performance level. Throughout the data analysis, especially the first author, who is of German origin but had been living in the UK at the time of data collection, paid attention to possible crosscultural differences which are addressed within the results and discussion sections. depth information on the topic of interest while, at the same time, collecting a range of experiences within diverse sport environments. In addition to holding a recognized

171 qualification in sport psychology within the respective country ${ }^{1}$, participants were required to 172 have at least three years of practical work experience delivering sport psychology services to 173 athletes and coaches within high-performance sports (e.g., international level; professional sports). Moreover, participants had to confirm previous circumstances in which they were confronted with coach-athlete conflict in their role as a sport psychology provider. These criteria were chosen above and beyond the minimal accreditation requirements as these differ

177 between both countries. This way, similar baseline levels of consultancy experience could be 178 guaranteed. Overall, participants in this study had been delivering sport psychology services between 5 and 43 years; averaging a work experience of 14.6 years (German sample; 5-43 years) and 13.0 years (British sample, 5-22 years). They had worked within various settings,

\footnotetext{
${ }^{1}$ BPS Qualification in Spot and Exercise Psychology - Stage 2/ BASES chartered sport and exercise scientist; sport psychological expert with the Germany Society of Sport Psychology
} 
181 including freelance work with individual athletes and coaches, as part of Olympic/

182 Paralympic (e.g., canoeing, beach volleyball, gymnastics, diving, skiing) associations as well

183 as within professional sport teams (e.g., football, handball, hockey). It should also be noted

184 that the majority of British participants worked solely within sport, while German participants

185 could draw on a variety of professional experiences within clinical or organizational settings.

186 Participants further based their practice on diverse philosophical beliefs and practical

187 approaches (e.g., solution-focused coaching, humanistic approaches), and also differed in

188 regards to their own prior involvement in sports (i.e., performance/coaching level).

\section{Data collection}

After ethical clearance was obtained from the authors' university's ethics committee participants were contacted via standardized emails, via telephone or personally. They were

191 informed about the content and purpose of the study, made aware that interviews would be audio-recorded and parts of the data may be used for scientific publications under which circumstances their anonymity would be protected. The interview guide was based on previous research into interpersonal conflict in sports (e.g., Holt et al., 2012; Wachsmuth et al., 2017) and contained 26 questions across four parts: 1) a main introduction, 2) SPPs perception about coach-athlete conflict and their role within it, 3) challenges in dealing with coach-athlete conflict, and 4) a reflective summary and outlook.

Before each interview, participants were asked to provide basic demographic

information, such as experience as a SPP and work conducted in other fields; they were also 200 given a short summary of the interview process. The introductory questions of the interview

201 focused on participants' development as a SPP covering one's professional training,

202 philosophical approach and views about the importance of coach-athlete and client-SPP

203 relationships. This first part aimed to create a comfortable atmosphere and facilitate

204 researcher-participant rapport, as well as to help develop an understanding of participants'

205 perspectives on working with coach-athlete dyads. Within the main part of the interview, 
questions covered SPPs' experiences of coach-athlete conflict (e.g., "What different conflicts between coaches/athletes have you experienced in your work as a SPP?") and their approaches to prevent and manage coach-athlete conflict (e.g., "What methods do you employ to prevent or manage conflict? What is your role during an episode of ongoing coach-athlete conflict?"). Subsequently, participants were asked to reflect upon barriers or challenges they

211 perceived when managing coach-athlete conflict (e.g., "What ethical issues have you come

212 across when working with coach-athlete dyads in conflict?'). Finally, the interview concluded 213 with a reflective summary of the participants' account on coach-athlete conflict (e.g., "How 214 would you reflect on your experiences during coach-athlete conflict?") and an invitation to 215 share any other thoughts they may have had on the topic. Interviews lasted between 46 and 105 minutes $\left(M_{\text {duration } G E R}=65.5, M_{\text {duration } U K}=79.1\right)$

217 and equated to 491 pages of double-spaced transcripts. All interviews were carried out in 218 personal meetings ( $n=11 ; 46$ to $105 \mathrm{~min}$ ) or via Skype ( $n=5 ; 48$ to $90 \mathrm{~min})$. The semistructured nature of the interviews allowed for some degree of flexibility and as such ensured a naturally flowing conversation in which the interviewer had the opportunity to prompt

221 responses of participants to gain further in-depth information. Moreover, the study was led by 222 the first author who has experience in qualitative research and whose own sport psychology background further promoted rapport between interviewer and interviewees. Additionally, the main researcher was familiar with some participants which may have facilitated rapport with these individuals. However, no systematic differences regarding the length and depth of these 226 interviews were observed in such cases where the participant had already known the

227 researcher in some capacity. Notes taken during the interviews and as part of personal 228 reflections supported the data analysis process.

\section{Data analysis}

Thematic analyses. An inductive thematic analysis of all interview transcripts was conducted to identify common patterns across participants' reports (Braun, Clarke, \& Weate, 
231 2017). This was initially done separately for all participants, before a cross-case analysis was

232 carried out. The data analysis followed the approach forwarded by Braun et al. (2017). Thus,

233 the main researcher familiarized herself with the interviews by re-listening to the audio-tapes

234 as well as reading carefully through the transcripts. This also involved an initial semantic

235 (e.g., misuse of sensitive information) and latent (e.g., experiences of internal turmoil due to

236 conflicting expectations) coding of the data as well as taking reflective notes about the

237 researcher's understanding of potential questions about the data. Moreover, initial codes (e.g.,

238 opportunity to vent frustration, facilitate self-reflection, help understand other's perspective)

239 were explored to form connections between the participants' reports and as such to identify

240 shared, underlying concepts and patterns within the data set. This clustering process resulted

241 in a preliminary set of lower-order themes, for example, SPPs' function as a sounding board,

242 translator or consultant. Thereafter, connections were drawn between the lower-order themes

243 combining similar data patterns into larger organizing concepts (Braun \& Clarke, 2019; e.g.,

244 SPPs' role as an educator, facilitator, or protector). While here described in a linear fashion,

245 the process of clustering and re-clustering themes and subthemes underwent multiple

246 iterations. Additionally, all themes were critically reviewed by revisiting the original

247 interview transcripts in order to contextualize participants' accounts and thus add depth to the

248 interpretation of the researcher (Braun et al., 2017, 2019). Moreover, by placing participants'

249 quotes back into context it was possible to see as to whether these actually addressed the

250 theme they were intended to. Continuously engaging with the transcripts also ensured that the

251 generated themes were represented within the data meeting the pragmatist assumption that

252 warranted assertions (i.e., knowledge) need to be supported by sufficient reason. Within this

253 step, minor changes in the organization (i.e., hierarchy, clustering) of the themes were

254 undertaken before notes and preliminary descriptions were refined into final theme

255 definitions. These definitions encapsulated the essence of each theme and outlined the 
individual links to the main research question. Finally, higher-order themes were grouped into overarching themes (roles, challenges) marking the distinct structure of the data.

Methodological rigor. Several measures were taken to ensure rigor of the data analysis within this study. For example, the analyses were supported by reflective notes and visual maps of the data as well as regularly discussed with both co-authors to facilitate

261 reflection and critical thinking of the researcher (e.g., Braun et al., 2017). By initially analyzing every interview individually equal attention has been given to every single participant rather than creating themes based on few salient examples (Braun et al., 2017).

Moreover, independent sport psychology practitioners and researchers acted as critical friends in the final stages of data analyses (Smith \& McGannon, 2017). The critical feedback offered on the results supported the definition and structuring of final higher- and lower-order themes.

267 Overall, the developed themes provide a coherent account (Smith \& Caddick, 2012) of how 268 SPPs can support coaches and athletes in preventing and managing interpersonal conflict. They describe distinct roles and approaches to dealing with such difficult situations and also consider situational circumstances, such as environmental barriers and individual challenges.

271 Aligning with the pragmatist perspective and based on the concept of natural transferability

272 (Smith, 2018), the audience of this paper may recognize parallels to their own professional 273 experiences and derive practical knowledge for their sport psychology practice from the 274 findings of this study.

\section{Results}

The thematic analysis resulted in the two overarching themes of sport psychology

277 practitioners'(a) roles in managing coach-athlete relationships (6 subthemes; see figure 1)

278 and (b) perceived challenges (5 subthemes; see figure 2).

\section{Sport psychology practitioners' roles in managing coach-athlete relationships}

The first higher-order theme covers six distinct lower-order themes describing the perceived roles and responsibilities of SPPs in preventing and managing conflict between 
281 coaches and athletes. It should be emphasized that most participants referred to all of these

282 roles across different conflicts with different coach-athlete dyads. However, the extent to

283 which practitioners engaged in these roles differed between particular instances of conflict.

The SPPs as an educator. As an educator, participants explicitly provided

information (e.g., in presentations, continued professional development, formal workshops) to

287 athletes and coaches which they deemed important for conflict prevention and management.

288 These were oftentimes one-off sessions covering a wide range of topics directly or indirectly

289 related to interpersonal conflict. While some topics were perceived relevant to either athletes

290 or coaches, a set of topics could be identified as essential for both. These core topics included

291 communication and conflict skills (e.g., expressing personal needs, active listening), self-

292 regulation (e.g., managing own emotions), personality (e.g., personality profiles), and stress 293 management skills, with one German participant stating:

I'm working in coach education. So in Basketball one aspect is self-regulation, so coaches learning to regulate themselves. I'm also doing that for the coach academy in [city], there I'll also talk about work-life balance and cover communication strategies. (GER-4)

298 Overall, SPPs reported a wide range of topics related to conflict which they may cover within coach education. Depending on the needs of clients and the educational setting (, small groups, CPD courses) the content varied between areas of social psychology (e.g., leadership, 301 group dynamics), developmental psychology (e.g., development of attachment styles and 302 effects on individuals' self-regulation/interpersonal skills), psychodynamics (e.g., emotional 303 suppression, counter-/projection), as well as consultancy skills (e.g., caregiver sensitivity, 304 Littlefoot approach; Petitpas, 2000). Conflict was highlighted as a process that naturally occurs within relationships, especially within high performance environments, with one

306 British participant emphasizing the importance of general education in this context: 
[We] try to raise awareness through education. So actually to come in and normalize dysfunction by understanding human development and human behavior in performance contexts. So in terms of when we put ourselves into pressured environments or pressured systems. [...] You can come in at a level which is education for everybody and through that hopefully people can recognize some of what you are talking to and see it in themselves, see it in people they work with. And that gives permission to be spoken about more generally. (GB-7)

While also covering a few aspects of social psychology (e.g., group dynamics/team building)

within athlete education, SPPs mainly focused on psychological skills (e.g., traditional mental

317 skills, acceptance commitment training), and coping with set-backs or negative feedback. For example, a German SPP (GER-4) offered "a workshop at the Olympic training center with the topic 'Dealing with criticism' [...] the aim was to train unambiguous communication."

Overall, these educational sessions introduced important information and basic competencies,

321 however, they were not set up for guided skills development nor did they intend to manage an 322 explicit case of coach-athlete conflict.

The SPPs as a consultant. In contrast to the role of an educator, participants focused on long-term skill development (e.g., communication skills) and individualized problemsolving (e.g., dealing with undesired behaviors) when engaging in the role of a consultant.

Accordingly, they mainly worked with small groups or individuals over a prolonged period of

327 time on a specific problem or skill set. For example, participants mentioned how they aimed at improving the quality of coach-athlete relationships by developing the social skills necessary to build these connections: had an agreement with the coach "This young man needs guidance as to how to 
shape social processes" - he doesn't have any idea how to keep agreements or solve conflicts. (GER-5)

334 This process often included the development and practical training of communication 335 strategies as outlined by one of the British SPPs: I have a real responsibility to upskill other members of staff, to upskill coaches, to upskill the physios and sport scientists around things like managing conflict or how to deal with relationship conflicts and building support networks for those different people within a high-performance environment. (GB-5)

In regards to coaches, an emphasis was put on the development of leadership skills and an

341 optimal team environment. However, while SPPs perceived that "The best work you'll do is 342 working through coach and cultivating that climate" (GB-7), the work with coaches often 343 proved to be challenging and frequently required a less direct, more tacit nudging approach 344 (e.g., providing bits of information, indirect suggestions, reinforcing desired behaviors). Yet, it was not always possible to work with coaches or influence the overall team

346 environment, therefore, participants described how they would work on improving athletes'

347 mindset, motivation, and assertiveness over the course of multiple individual sessions. For 348 example, one athlete received "assertiveness training $[\ldots]$, three or four sessions $[\ldots]$ get them 349 to understand that [talking to the coach] was achievable and possible, and the technique that they could use to try to do that" (GB-6). However, SPP consultancy was not only important to 351 prevent conflict, but also to cope with conflict and its potential negative consequences, for 352 example, by strengthening individuals' coping mechanisms (e.g., gaining distance, managing emotions, seeking support).

The SPPs as an analyst and action planner. Whereas the first two roles as an educator and consultant included a direct focus on conflict as well as a more general developmental approach, SPPs' function as an analyst and action planner refers to specific 357 conflict events. Thus, as an analyst and action planner participants aimed at a) identifying and 
assessing explicit situations of conflict within coach-athlete dyads, b) analyzing the reasons

359 for these conflicts, and c) developing strategies to manage specific coach-athlete conflicts.

To identify (potential) conflict, participants observed individuals' behaviors (e.g.,

361 body language) and coach-athlete interactions (e.g., communication), as well as assessed

362 situational and personal factors which would contribute to conflict (e.g., perceived stress,

363 personality). Often, SPPs were also directly approached by coaches and athletes asking for

364 advice. Participants further explained how they would aim at gathering information, for example, via observations or interviews in order to understand the complexities of the specific conflict event. A German SPP emphasized the importance of a "clean diagnosis" by “primarily doing training observations [...and] conducting interviews and having conversations with coaches and athletes, and if necessary also using a scale" (GER-7). Formal psychometric tools like personality tests were mainly used by British SPPs to support the assessment process, but also to identify potential areas of future conflict (e.g., due to contrasting values, personality characteristics or communication styles) for which 'What-if scenarios' could be created to avoid a potential escalation: You can always pre-empt the conflict, it's hard to find the time and space for this, but if you do, you can really plan on "what situation might occur?" and "how can we support that before it happens?" [...] it comes down to having that

378 Within individual or small group sessions, SPPs further aimed at analyzing conflicts by 379 defining the core problem, inquiring about conflict promoting factors and identifying potential 380 solutions. Some British participants referred to multidisciplinary team case formulations 381 which they either took part in as a staff member or led as an external consultant: One thing that we try and do is what we call a MDT case formulation, where we have, so the player in question that we are kinda looking to discuss, we will 
normally have the two coaches that work with the player, the sport scientist, the video analyst, myself as a psychologist and who often facilitates that session is my boss [senior SPP] who is less involved -and we'll review the conflict as a MDT and try and resolve why this conflict is occurring, so why this player is struggling with this relationship or is struggling with his position in the team, information sharing through what we call an MDT case formulation conference - we all sit around the table, we share information, we identify what needs to change, what are the action points. (GB-5)

An integral part of these MDT case formulations seemed to be the compilation of an action plan which coaches and staff members were encouraged to comply with to solve conflicts with specific athletes. Similarly, SPPs reported planning further actions with individual clients whereby they usually focused on the performance-oriented purpose of the coachathlete relationship but also considered the wellbeing of conflict parties. SPPs gave detailed insight about the content of these individual conversations which covered, for example, considerations about one's own and the other party's goals, specific behavioral strategies to achieve these goals, as well as planning and practicing communication strategies to approach an issue with the conflict partner:

What I do is to think, together with the athlete, about possible solutions. So initially we may look at "What was that actually supposed to mean?!" We work together on the possibility to directly address it, so to say or ask something. Maybe also consider a behavioral experiment, depending on whether it is actually just a concern that the athlete may have. However, a lot of the time athletes seek a conversation alone and we prepare before what say want to say and also practice it in the form of a role play. (GER-4)

The SPPs as a counsellor. Compared to the previous three themes in which participants adopted a practitioner-led approach, the role as a counsellor describes a rather 
410 client-led approach to manage specific situations of conflict usually working with only one of

411 the relationship members. For example, one participant shared "All I'll ever do generally

412 speaking is listen, offer opportunities to reconnect with that person, but most of all, hold up

413 that mirror. I find people get to their own conclusions quite quickly" (GB-4). Further, SPPs

414 reported how they acted as a sounding board for athletes and coaches and as such provided

415 opportunities to openly express emotions and vent frustration as well as a safe place for

416 "saying what cannot be said" (GB-7). Thus, an important element of SPPs' role as counsellor

417 was to facilitate self-regulation and self-reflection. This included realizing that one's

418 perception may be "a truth but not the truth" (GER-5) and reflecting upon the questions

419 'What is my part in the conflict?' and 'How do I come across?'. As a result of these

420 conversations, athletes and coaches further analyzed the situation with SPPs or made their

421 own conclusions about how to approach conflict so that often no further action was needed.

422 One participant (GB-2) recognized that "sometimes in conflict, there can be a cooling off

423 period, it doesn't necessarily need an intervention" and explained "sport is pressured, it's a

424 pressurized environment, as it should be in such a competitive arena, so conflict is possibly

425 just a by-product of the environment."

The SPPs as a facilitator. However, at times SPPs perceived it as necessary to

427 directly intervene in coach-athlete conflict. Overall, three different approaches were identified

428 which aimed at enhancing interpersonal processes between sport participants; these ranged

429 from initiating coach-athlete conversations to moderating group sessions and usually involved

430 working with all conflict parties, either individually or mutually together (cf. counsellor).

$431 \quad$ Forming a bridge between coaches and athletes. An important part of this role was to 432 increase mutual understanding, thus, SPPs often acted as a translator of individuals'

433 personality or helped to understand different opinions by asking directive questions,

434 explaining complex situations or challenging individuals' ways of thinking. One participant 
described a severe conflict occurring during a major competition which caused a complete breakdown of communication between a coach and their athletes: It was mainly about trying to make them understand how the other perceived the situation. I think that was the most important part, simply to explain the athlete why the coach and NGB reacted like they did. And then [the athlete] defended herself, did the same with the other athlete, and then I needed to explain the athletes' position to the coach. So I think, I was more supporting communication because they couldn't manage themselves. (GER-9)

SPPs further formed a bridge between coaches and athletes by focusing on common values and goals as well as explaining individuals' behavioral preferences. Thus, SPPs enabled them to better adapt to one another, especially under stressful or pressurized circumstances: The athlete is now valuing the coach very differently based on the work we've been doing on perceptions and evaluations. For me it's not necessarily trying to tackle the conflict itself, it's about aligning those two individual outcome beliefs, values and core principles. It's about synchronizing their beliefs, that's when you see people thriving in an environment, and the conflict becomes very healthy in a challenging way. (GB-3)

In contrast, few participants also mentioned how it was vital to continuously manage the relationship between coaches and athletes who were involved in long-term, seemingly unresolvable conflict:

Now in the second year of being involved with the team it is working, there is still friction, but with many conversations and lots of balancing out between them it's working, never with both of them - the relationship is too fragile, I always have to get them back on track individually. (GER-2)

Catalyzing conversations. Building on the work with the individual conflict parties as described above, SPPs also encouraged their clients, especially athletes, to seek open and 
461 honest conversations and emphasized the importance of addressing concerns early on.

462 Participants highlighted how they actively created or even staged possibilities for these 463 conversations to take place. One participant (GB-6) pointed out that "when [conflicts] do get 464 talked about then normally because someone like myself [SPP] created an opportunity for 465 that [conversation] to come out, and paved the way for that opportunity to be perceived 466 positively and looked upon as a way forward". German SPPs further mentioned that they 467 had sometimes addressed conflict directly with one or both parties, especially "if only one 468 party is aware of the conflict" (GER-1). Depending on the quality of the SPP-client relationship they would use a more or less confrontational approach and sometimes only hint at problems to not break confidentiality. For example, SPPs "would try to sensitize and bring

471 them back together", for example, by asking them to reflect upon recent interactions with the 472 athlete/ coach, or "nudge the one who is not seeing the conflict and say 'Look, there might 473 be an issue' [...]". However, the same participant stated that "it may also be that I tell the coach or athlete" (GER-1), thus breaching confidentiality for the sake of conflict resolution.

475 While these incidents were rare, participants justified such behavior as means to an overall 476 positive end (see perceived SPPs' challenges). Accordingly, one concern that all SPPs 477 shared was athletes`safety, accordingly, participants only encouraged open conversations 478 when they perceived coaches would be approachable and fair (also see role as a protector). Mediating and moderating coach-athlete interaction. As a mediator of coachathlete meetings or moderator of group sessions, SPPs were directly involved into

481 conversations aiming at resolving coach-athlete conflict. They described to be primarily 482 responsible for providing structure within such meetings, guiding conversations and 483 ensuring a safe and positive environment in which people were willing to openly share their 484 thoughts and feelings. Within group sessions that was usually achieved by discussing 485 problems without necessarily focusing on a single athlete, but rather by talking about 
concerns shared by multiple team members. A British participant (GB-6) explained their

487

However, participants did not strictly differentiate between formal, task-oriented mediation processes and more informal meetings, in which conflict parties focused on improving their

511 overall relationship (i.e., third party consultations) as described by a British participant: 
One of the biggest challenges I've ever faced is one of the most beneficial bits of work I've done [...] to have conversations about expectations, having structured conversations about "what do you expect" and "what do I expect" What you work out through the communication process, when you have conversations about expectations, the conflict in that relationship quite often becomes more realigned and more conducive to a happy environment. (GB-3)

The SPPs as a protector. Lastly, the role as a protector as described by participants encapsulated concerns about meeting conflict agreements which had been accepted by both conflict parties as well as about individuals' wellbeing throughout times of conflict. As such

521 participants aimed at securing a nourishing and effective training environment for all sport 522 participants without losing sight of individuals' needs.

Thus, SPPs tried to establish and maintain such a healthy environment by noticing and managing dysfunctional interpersonal processes, as well as by ensuring that conflict agreements were adhered to or revised. This was achieved by implementing and monitoring behavior change, utilizing debriefs to facilitate self-reflection and learning as well as by

527 holding individuals accountable for failures to comply with agreements.

528 I'm the one who then does a bit of a debrief following that session, to be like these were the key things that came out, these are the key things that we said we [are] gonna do, these are the things that you need to put in action and we will have a follow up meeting to evaluate this. [...] I try to set up regular catch ups with them individually, just keep track of how things are going and just be on the ground and get some observation work in [...] you're not seeing him having stuck to his part of the deal, haven't done the thing he said he was gonna do $[\ldots]$ maybe at times having a conversation $[\ldots]$ boost them a little bit there, so I think being on the ground and being around could be a bit of leverage itself in terms of reminding them actually. (GB-5) 
538 On the other hand, SPPs also emphasized their responsibility to ensure athletes' safety. As 539 mentioned briefly before, SPPs discouraged athletes from seeking conversations with coaches

540 or staff members if they expected negative consequences (e.g., deselection, aggressive

541 behaviors, belittling), and similarly limited their own communication based on the likelihood

542 that shared information would be misused against athletes; one participant warned:

You have to be realistic about levels of safety in different environments and consequences of these conversations for people's selection or deselection. I think it's fair to say for us as a process of providing that facilitation that we are assessing all the time in the moment levels of safety in the way the conversations are happening, we would be more than comfortable to say that 'Okay, maybe we should stop this process' if it feels like it's used unhelpfully - either in the interest of the system or in the interest of the athlete. (GB-7)

\section{Sport psychology practitioners' perceived challenges}

Across five sub-themes the second higher-order theme covers information about the challenges and barriers perceived by SPPs when trying to prevent or manage coach-athlete conflict, including environmental, situational as well as profession-related aspects.

Procedural factors. A fairly common challenge experienced by SPPs was tailoring interventions to the specific coach-athlete dyad and situational circumstances. Factors that needed to be taken into account were, for example, characteristics of the involved individuals

557 (e.g., age, personality, type of coach, status) as well as available resources to successfully 558 manage conflict. Participants, for example, identified lacking time as an inhibiting factor for 559 effective, long-term conflict resolution as described by a British SPP who found that "getting time with the athlete" is problematic "cause their schedules are so ram-packed [...finding] 
can be quite difficult." Another aspect that needed to be taken into account by SPPs was the importance of a conflict and the urgency of its management as perceived by conflict partners: ...the other thing that historically I haven't dealt with well, but I do far better now, is not put a time limit on when it needs to be resolved by. Some things do just linger on, but people are fully happy and fully functional but they still have underlying conflicts, that conflict may never need to be resolved. But that sense that everything needs to be fixed by me and now, that, I now avoid. (GB-4)

Besides the significance of the conflict topic, also the importance and quality of the

relationships between the conflict parties as well as with the SPP need to be considered. Thus,

571 often participants were indeed only working with one individual (often the athlete) or had

572 unequally well-developed relationships with the conflict parties, as shared by one practitioner: I still didn't feel the capacity to provide that feedback to the coach. I did voice the concerns to the athlete and at times did agree with his initial questions about his relationship with the coach. (GB-3)

In line with above provided quote, the role of a facilitator was primarily occupied when SPPs

577 either have had established relationships with coaches and athletes (e.g., possibilities to

578 initiate conversations or "translate" perspectives) or were brought in as an external "more 579 neutral" consultant (GER-1). The latter, however, carried the danger of not knowing personal 580 characteristics or even hidden objectives of conflict parties. Thus, SPPs always needed to be 581 aware of individual agendas, including skepticism as to whether conflict parties were honestly

582 interested in solving a dispute or simply pretended to be engaged in the process as

583 experienced by a German participant who pointed out that "it is a difficult situation if you 584 notice that one party doesn't mean it, for example, that the association cooperates pro forma 585 but if in doubt would stab the athlete in the back" (GER-1). 
The sport environment. In line with the previous example, some of the most severe barriers concerned the sport environment of which SPPs were part of, for example, in regards to SPPs' role within the organization and sport participants' welfare.

Welfare concerns. SPPs continuously emphasized the need to ensure coaches and athletes' wellbeing. However, at times they perceived to be caught between their duty of care 591 and the sport organizations' performance focus. This was especially the case if conflicts were 592 caused by coaches' use of controlling or even abusive behaviors; GER-8, for example, described how they quit their job after watching an athlete "being pushed towards burnout" by a coach that only cared about performance. Nevertheless, SPPs' concern was not only with athletes but also with coaches' wellbeing who may experience "personal trouble with the association in that they have already achieved two gold medals but don't get their contracts

597 extended" (GER-2). Thus, SPPs recognized that coaches' interactions with athletes were 598 influenced by a constant insecurity within a highly-pressurized environment as well as by lacking leadership and organization within the sports associations, however, intervening on an organizational level was usually beyond the means of the interviewed SPPs. Considering the

601 wider sports environment, SPPs had to weigh up the likelihood of positive change against 602 negative consequences when intervening in coach-athlete disputes. If action was taken, SPPs 603 had to anticipate how information was used and which consequences were to be expected: Honesty and openness, that understanding of someone else's perspective on something is really undervalued and, I think, dismissing of that as a pattern of behavior in the sporting environment is often the root of that perpetuated conflict. No one is allowed to be honest, no one is allowed to be open - just shut people down - that just creates a whole world of pain and once you chip away all that or allow that honesty then you can get over quite a lot. (GB-6) 
SPPs' role within the organization. SPPs further perceived their position to be reliant

611 on coaching and management staff (e.g., contracts, access to athletes, type of work) which

612 restricted them in carrying out their job as they desired; one participant (GB-1) explained: of the club. You go and then find out that a large amount of the environmental, organizational trouble within the club, is [caused by] the person who employed you which is a huge dilemma, I tried to do it sensitively, because we had a good

to intervene in coach-athlete conflict; it was explained that "if you are between the two it' $\mathrm{d}$ be your task to satisfy both, but that's really not your job" (GER-3); but another (GER-2) argued: need to watch out for who is deciding whether a sport psychologist will get involved or not - the coach. Therefore, sport psychologists walk on eggshells how often do they confront coaches saying "What you are doing in nonsense, you're treating [the athlete] like crap, you're not taking them seriously at all,

\section{Correspondingly, SPPs often reported being considered part of the coaching team and}

629 therefore were assumed to always side with the coaches in times of coach-athlete conflict.

630 Paradoxically, participants described how they often worked in isolation and did not feel

631 accepted by staff members and thus could not contribute much to coach-athlete relationships 632 due to their personal lack of high quality working relationships within the sport organization.

633 Even more difficulties were experienced when SPPs were not part of an organization at all but 634 rather acted as an external consultant and worked only with one conflict party, usually the 
635 athlete who "don't want their coach to be involved" (GER-7). Therefore, they often lacked

636 information of and influence on at least one, if not both, conflict parties.

Objectivity versus appropriate support. Another frequently reported theme, which

638 in some extent related to the above outlined role of SPPs within the sporting organization,

639 concerned their ability to be objective during coach-athlete conflict:

Sport psychologists need to work with the coaches as well as the players because somewhere in the middle of those two perceptions is truth, and sometimes neither party can see the truth $[\ldots]$ the dilemma for a sport psychologist is being part of the team but not being so emotionally engaged that you become part of the problem. (GB-1)

Thus, while it was generally deemed appropriate to not side with either conflict party, participants perceived it as challenging to keep neutral based on their previous involvement

647 with conflict parties (e.g., one-sided relationships; part of coaching team). One participant

648 even considered it "a disadvantage to be part of the system as you lose the outside

649 perspective" (GER-8). Moreover, athletes and coaches tended to take SPPs' support for

650 granted, presuming that SPPs "had their back" - not meeting these expectations could

651 potentially cause "a crack in the coach/athlete-sport psychologist relationship" (GER-1). And

652 while participants acknowledged to sometimes position themselves on either side, they

653 highlighted several factors worth considering when deciding where to place themselves

654 during coach-athlete conflict, or whether to stay out of it entirely. For example, it was

655 "important to not worsen the coach-athlete relationship through one's own actions" (GER-6)

656 as well as to "put performance in the center of everything you do" (GB-4). Thus, SPPs

657 sometimes believed it was appropriate to clearly align oneself with coaching staff, for

658 example, if SPPs were an established part of the coaching team, the majority of athletes

659 worked well with a certain coach, or if an athlete had a negative impact on the training

660 environment. In contrast, SPPs supported athletes if multiple individuals struggled with a 
661 certain coach, coaches were overstepping role boundaries and athletes needed to be protected,

662 or if SPPs did simply not work with the respective coach.

Rigid beliefs. Part of SPPs' struggle to effectively manage coach-athlete relationships

664 was caused by athletes and coaches' rigid beliefs. While athletes on "the world class level see

665 the coaches as an unchanging part of the environment $[\ldots]$ they don't see the coaches as

666 adapting or flexing at all" (GB-6), coaches were indeed often "confident of their approach"

667 and "very resistant to information to how they might change to do things" (GB-6) or had

668 difficulties converting advise into action. Especially during deeply-rooted conflicts, positions

669 between the conflict parties increasingly hardened so that any mediation attempts by SPPs

670 were prone to fail. Participants explained coaches and athletes would shift responsibility to

671 each other - the athlete saying "the coach needs to see that, that's his responsibility" and

672 coaches expecting the athletes to speak up - and as such creating "a barrier that is hard to

673 overcome when individuals are unwilling and stubborn" (GER-8). Sometimes these

674 stalemated conflicts could only be settled if, encouraged by SPPs, "the management of the

675 sport organization takes the lead" (GER-2).

676 SPPs' professional challenges. Finally, SPPs perceived their effectiveness in

677 managing coach-athlete conflict to be inhibited by their own training and working philosophy.

678 Thus, most participants emphasized how they lacked formal training in conflict management

679 and were therefore hesitant to act as a mediator, especially if they expected the conflict to

680 further escalate. Accordingly, participants at times refused to get involved as GB-4 reported:

681 It's about what is and what's not in the job description, conflicts where it's quite

682 obvious that I can't resolve it, are things I've learnt to avoid in the first few years

683 of my career. I think recognizing if you can have an impact in the first place.

684 Further, participants were challenged by their ambivalent position towards confidentiality.

685 While underlining the importance of not sharing confidential information and standing up to

686 coaches who demanded such, SPPs felt limited in their possibilities to manage conflict: 
I think there is a risk that confidentiality is sometimes used as a barrier to talk about something that is actually already known in the group, and probably what we are talking about there is that the athlete likes to have a good moan about the people in the system and that then the SP feels a bit that they are in a difficult position cause if they tell the system that information that could come back to be used in a negative way against the athlete. (GB-7)

693 Therefore, participants weighed up between the long-term benefits of sharing some information for the coach-athlete dyad versus keeping confidentiality and trust within their own client-practitioner relationship. Few SPPs mentioned how they would extensively discuss the matter of open communication with the individual in order to resolve the dilemma: At first [the athlete] was very reluctant to the coach to know any of the information that he disclosed, so we did a lot of work prior to this to get to the stage that he [would allow disclosing] information to the coaches. (GB-5)

\section{Discussion}

The aim of this study was to gain in-depth insight about the roles and approaches SPPs

701 take when working with coach-athlete dyads in conflict. This also included exploring SPPs'

702 perceptions about the challenges they had to face in respect to the types of service delivery 703 they provide. Thus, this study ultimately builds upon previous research outlining applied sport psychologists' roles in managing interpersonal and intragroup relationships in sport (e.g., McDougall, Nesti, \& Richardson, 2015; Vealey, 2017) and further aligns with findings according to which sport participants sought out third party help to manage conflict

707 effectively (e.g., Holt et al., 2012; Wachsmuth et al., 2018). It further extents the applied sport 708 psychology literature which so far has focused on coaches and athletes' perceptions about sport psychology delivery (e.g., Cook \& Fletcher, 2017; Zakrajsek et al., 2013), interventions

710 (e.g., Martin et al., 2009), or experiences of applied sport psychologists in the build-up or

711 during major competitions (cf. Arnold \& Sarkar, 2015; McCann, 2008). Thus, this study 
712 enters uncharted territory by offering first-hand information on SPPs' approaches to optimize

713 coach-athlete interactions. The findings are expected to support consultants' professional

714 development and provide guidance through this challenging task.

715 In accordance with research in- and outside-of sport (e.g., Jowett \& Shanmugam,

716 2016; McDougall et al., 2015), the present study underlined the importance of high quality

717 working partnerships in which relationship members are appreciative and accepting of another

718 realizing that they ultimately support each other in their quest to achieve a common goal.

719 Subsequently, SPPs' endeavor to support athletes and coaches to develop and maintain

720 harmonious working relationships underlined by open lines of communication and mutual

721 trust. Besides creating awareness for the importance of close, committed and collaborative

722 relationships, they actively supported this process by developing communication skills in

723 regards to sending well-constructed messages (e.g., needs, concerns), listening skills (e.g.,

724 active listening), perspective taking as well as appropriate responding. These approaches align

725 with established conflict resolution training programs as, for example, provided by Coleman

726 and Prywes (2014) who combined conflict education (e.g., conflict processes) with skills

727 training (e.g., communication, self- regulation) within diverse community settings.

728 The findings of this study also offer insights in terms of managing conflict

729 determinants, such as personality characteristics, maturity, and stress. For example, a clash of

730 different personalities has frequently been referred to as causing intense interpersonal conflict

731 (e.g., Paradis, Carron, \& Martin, 2014; Vealey, 2017; Wachsmuth et al., 2017), but can

732 potentially be prevented by raising awareness for one's and others' personality and their

733 behavioral tendencies (cf. Arnold \& Sarkar, 2015). Similarly, coaches were supported in their

734 work with diverse groups of athletes, not only by increasing their ability to adapt to different

735 personalities, but also by creating a holistic understanding of psychological and interpersonal

736 processes in regards to leadership, group dynamics, and human development. An emphasis

737 was further put on coaches' personal wellbeing through enhanced self-care (e.g., work-life 
738 balance; coping with environmental pressure; stress management), an aspect that coaches felt

739 was neglected by sport psychologists within former studies (e.g., Cook \& Fletcher, 2017).

740 Overall, SPPs seemed to equip coaches with skills and knowledge which aimed to increase

741 their psychological and behavioral flexibility, and thus, facilitated conflict prevention as well

742 as coaches' ability to guide through conflict management in a rational but caring manner.

743 Athletes, on the other hand, seemed to be taught skills which enabled them to react to and

744 cope with conflict (e.g., assertiveness, communication, mental skills and coping strategies).

745 Although athletes may also benefit from an education focusing more on conflict prevention,

746 these two different educational approaches and the differening emphasis placed on each

747 approach reflect the reciprocal roles of coaches and athletes within their overall relationship

748 (e.g., Jowett \& Shanmugam, 2016; Becker, 2009).

\section{Third party interventions in coach-athlete conflict}

While it is common practice for sport psychologists to offer a wide range of

educational work, including some of the above outlined areas, little attention has been paid to

751 their role within interpersonal conflict (cf. Vealey, 2017). The results of the present study,

752 however, suggest that sport psychologists may indeed play a crucial part in solving coach-

753 athlete disputes effectively. Accordingly, participants' reports outlined a range of roles and

754 practical approaches to support sport participants in their efforts to cope with disputes and to

755 find commonly acceptable solutions. SPPs attempted to do so by working with conflict parties

756 individually as well as dyadically. On an individual level, athletes and coaches used current

757 participants in an attempt to regulate emotions, for self-reflection as well as to shed light on

758 the complexities of ongoing conflicts, but also to provide reassurance and improve one's

759 coping mechanisms. Thus, rather than purely focusing on specific performance-enhancement

760 strategies as hired for by coaches (e.g., Wrisberg et al., 2010), SPPs provided a much broader

761 range of counselling and consultancy services, recognizing that "everything is a performance

762 issue" (McCann, 2008; p. 267) - not just during the Olympics. Further, participants in this 
763 study also thought dyadically (cf. Rhind \& Jowett, 2012) trying to bring coaches and athletes 764 closer together by bridging the gap between them. As previously described in the literature 765 (e.g., Mellalieu, Shearer, \& Shearer, 2013; Wachsmuth et al., 2017), participants recognized 766 that conflict was often down to a breakdown of communication which caused a split in the 767 coach-athlete dyad. In accordance with Vealey (2017), SPPs considered it as one of their main 768 responsibilities to overcome these communication barriers by improving individuals' 769 interpersonal skills, building trust, as well as by encouraging open and honest conversations 770 and guiding sport participants through these conversations. While participants only scarcely differentiated between the diverse conflict

772 management approaches that have been long established within the non-sporting literature, 773 several interventions became apparent through participants' reports. In line with Vealey's 774 (2017) descriptions of a conflict-ridden basketball team, sport psychology consultants in this study acted as a facilitator of interpersonal relationships. In early stages of conflict that meant, for example, acting as an "informal communicative link" between coaches and athletes based 777 on strong working alliances with their clients (i.e., conciliation; Fisher, 2001, p. 11). Thus, 778 they initiated communication processes by promoting problem understanding and regulating 779 emotions informally. However, if conflict progressed to a stage in which a coach's and 780 athlete's relationship declined and opposing positions formed, more formal approaches to 781 conflict management were deemed necessary which participants within this study often 782 described as mediation or moderation (cf. Holt et al., 2012). Considering the literature on 783 third-party interventions, however, it seems that SPPs in fact engaged in two different 784 approaches when working with coach-athlete dyads. While traditional mediation was used to 785 solve task-related conflict (e.g., Fisher, 2001; Holt et al., 2012), SPPs also acted as third-party consultants to facilitate the coach-athlete relationship quality. In line with the guidelines for such interventions (Fisher, 1972), participants aimed to minimize perceived threat and 788 increased individuals' motivation to seek conflict resolution by reminding on common goals 
and shared values, and facilitated effective communication by forming a shared understanding

790 of the conflict issue. Thus, the study supports previous suggestions (Paradis et al., 2014a;

791 Rhind \& Jowett, 2012) in that SPPs solved conflict by focusing on the task at hand

792 (mediation), and also met coaches' expectations of promoting interpersonal relationships

793 throughout difficult times (Cook \& Fletcher, 2017). Therefore, it may be concluded that both,

794 a task- as well as a relationship-focused intervention, may be constructive approaches to

795 manage coach-athlete conflict.

While these third-party interventions generally seem to provide a large pool of

strategies for sport psychologists to draw form, the appropriate line of action may depend on a number of variables, including to the stage of conflict escalation, the power distribution between the conflict parties, as well as individuals' skills and characteristics which were

800 likely to shape the conflict process (e.g., Coleman \& Prywes, 2014; Wachsmuth et al., 2017).

801 Therefore, Fisher (1972) emphasized the importance of holding contextual knowledge about

802 the conflict and the involved conflict parties, as well as possessing sound diagnostic and

803 interpersonal skills to clarify and overcome conflict resolution impasses or to offer emotional

804 support. In general, these characteristics have been identified as desirable for sport

805 psychologists by coaches and athletes (e.g., interpersonal skills, sport experience, rapport;

806 Cook \& Fletcher, 2017) and are met by SPPs within this study. Being part of the high-

807 performance environment, SPPs seemed to hold a sound understanding of the structural and

808 cultural context in which coach-athlete conflict occurred. Within their role as analyst and

809 action planner, participants made use of diverse diagnostics, such as interviewing, systematic

810 observations as well as psychometric assessments in order to gather the particular information

811 necessary to appropriately support coaches and athletes throughout conflict experiences.

\section{Micropolitics - diluting boundaries to facilitate positive change}


814 interventions. Thus, while possessing the knowledge necessary to support coaches and

815 athletes, Arnold and Sarkar (2015) warned practitioners to not intervene simply to prove one's

816 competence but to find the appropriate time and approach to do so. Indeed, participants in the

817 current study often seemed to be hesitant and were challenged by deciding whether and how

818 to promote conflict management within coach-athlete dyads. Often, these struggles were

819 attributed to environmental or structural factors (cf. McCalla \& Fitzpatrick, 2016), such as

820 practitioners' roles within an organization, their dependency on coaches and management

821 staff, or their perceived lack of influence on conflict parties. Overall, the (micro)political

822 landscape influenced SPPs' perceived possibilities of intervening in coach-athlete conflict.

823 Micropolitics hereby refers to "the use of formal and informal power by individuals and

824 groups to achieve their goal" (Blase, 1991, p. 11) with power being determined by the

825 availability of resources and the quality of relationships within a certain, potentially

826 conflictual, situation. Participants of the current study felt restricted in their possibilities to

827 manage interpersonal conflict effectively due to the power differentials and formal hierarchies

828 existing within sporting organizations (McCalla \& Fitzpatrick, 2016; Rowley et al., 2018).

829 While mediation, for example, is understood to be a means to equalize power distributions

830 between conflict parties (Kressel \& Pruitt, 1985), this is only possible if the mediator (i.e.,

831 sport psychologist) can indeed act independently. However, SPPs' independence was not just

832 limited by their link to coaches (e.g., influence, access, job security) or one-sided working

833 relationships with athletes, but also due to the expectations of management boards and their

834 power to distribute resources (e.g., finances, time, status). SPPs, moreover, were at risk to be

835 used for the micropolitical actions of others (i.e., coaches, athletes, staff) who at times tried to

836 use their established relationship with practitioners in order to gain an advantage over the

837 opposing party within conflict negotiations. McDougall et al. (2015) highlighted the challenge

838 of managing these multiple relationships and meeting the accompanying expectations of a

839 diverse range of individuals within elite sporting environments in order to effectively deliver 
840 sport psychology services. Similarly, the current participants, who had also been involved in

841 high-performance sports, emphasized the necessity of building close working relationships

842 with athletes, coaches and other staff members, and thus, to reduce existing boundaries and

843 promote team unity prior to difficult conflict interventions. This process included clarifying

844 how sport psychologists positively contributed to the overarching objectives of sporting

845 organization as well as creating a psychological informed environment (cf. Arnold \& Sarkar,

$846 \quad$ 2015; Haberl \& Peterson, 2006).

847 Being a fully integrated member of a sport organization, however, created further

848 challenges which largely related to ethical concerns such as conflicts of interest, objectivity,

849 or confidentiality (e.g., Andersen, van Raalte, \& Brewer, 2001; Aoyagi \& Portenga, 2010;

850 McDougall et al., 2015). For example, SPPs reported to experience internal conflicts as to

851 whether to act according to the sport organizations' performance expectations (i.e., winning at

852 all costs), personal interests (e.g., job security) or their duty of care for athletes and coaches

853 (e.g., burnout, injury), which impeded consultants' attempts to approach conflict objectively.

854 While participants were aware that true "objectivity" was barely possible, they still felt a

855 responsibility for taking everybody's interests into account and thus, for seeing the bigger

856 picture more clearly than conflict parties themselves. Further, internal conflicts also included

857 concerns related to confidentiality which seemed to be especially delicate in times of

858 interpersonal conflict during which SPPs often had to weigh up between keeping information

859 confidential versus breaching confidentiality as a mean to solve coach-athlete disputes. In line

860 with Aoyagi and Portenga's (2010) recommendations, participants in this study often

861 followed a best interest or stealth approach by either sharing confidential information or

862 nudging conflict parties in the right direction in order to facilitate conflict management and

863 promote effective coach-athlete relationships. Thus, participants acknowledged and embraced

864 the "blurry boundaries that exist in this setting" (Haberl \& Peterson, 2006, p.31). Always 
865 keeping the best interest of their clients in mind, sport psychologists overall aimed at creating

866 sport relationships which were positive and rewarding.

\section{Strengths, limitations and future directions}

In conclusion, this study aimed at investigating SPPs' roles and approaches to

869 preventing and managing coach-athlete conflict. The study hereby draws on a wealth of

870 experiences of sport psychology experts working within elite sport settings and looks beyond

871 traditional practices of mental skills training. It serves as a call for a more nuanced, process-

872 oriented investigation of sport psychology practice which may indeed be more concerned with

873 building effective interpersonal relationships with and between sport participants and thus,

874 shaping nourishing performance environments (McDougall et al., 2015). The current results

875 highlight the importance of creating psychologically informed performance settings in which

876 sport participants acknowledge the impact interpersonal relationships can have on sport

877 performance, wellbeing and personal development, as well as recognize the external (e.g.,

878 public expectations, cultural norms), intra- (e.g., personality, maturity, experience) and

879 interpersonal (e.g., leadership, communication, power) factors influencing the quality of these

880 relationships. As such, sport psychology services described within this study went beyond the

881 immediate management and resolution of interpersonal difficulties, but rather presented an

882 inclusive approach to promoting effective relationships. Thus, coach-athlete conflict was

883 considered a chance for learning and personal development, as well as a means to promote

884 change within the sporting environment (cf. Vealey, 2017). Recently, sport psychologists'

885 role in promoting cultural change became an area of research interest (e.g., Cruickshank,

886 Collins, \& Minten, 2013; Fletcher \& Streeter, 2016; McCalla \& Fitzpatrick, 2016),

887 considering this line of inquiry scholars may consider exploring how dyadic conflict could be

888 deliberately used to initiate and positively influence these larger organizational processes.

889 Further, studies investigating sporting environments and cultural change may consider how 
890 the process of "normalizing dysfunction" may break down communication barriers and 891 facilitate more open and collaborative working relationships within sport organizations. While this study did not aim at investigating cross-cultural differences between

893 German and British participants explicitly, subtle differences with regards to SPPs' work with

894 coaches and multidisciplinary teams could still be noticed. Thus, it seemed that British

895 participants spoke more frequently about working with and through coaches and staff

896 members than their German colleagues who, on the other hand, seemed to engage more in

897 formal mediation processes. A variety of reasons, such as consultants working philosophies,

898 training or simply their role within an organization could explain these differences. However,

899 more research is necessary to explore and compare distinct professional SP practices (e.g.,

900 formal approaches, habits, methods/techniques) and working possibilities (e.g., professional

901 roles, job structures) within different countries. Besides cultural differences, also the interests

902 of practitioners working in other settings than high-performance sports, such as youth sports

903 or talent development settings, as well as the needs of novice sport psychology consultants

904 should be taken into account when investigating more tacit processes involved in SP delivery.

905 These practitioners may face different or more amplified challenges with regards to building,

906 shaping and maintaining effective working relationships with athletes, coaches and staff (e.g.,

907 perceived lack of competence, career planning, financial security; McDougall et al., 2015;

908 Rowley et al., 2018). Considering the challenges outlined in regard to conflicts of interests by

909 the current - experienced - participants, more emphasis should be put on supporting (young)

910 practitioners in initiating difficult conversations, addressing unethical behaviors and

911 contesting widely established yet obsolete sporting practices (e.g., controlling coaching

912 habits, early-return to play). Overall, the current findings should thus be taken into account for

913 the education of future sport psychologists: Firstly, novice practitioners are likely to benefit

914 from a formal training in conflict management, mediation and other third party interventions.

915 Second, in line with recent calls for adopting a role closer to the one of an organizational 
Running head: THIRD PARTY INTERVENTIONS IN COACH-ATHLETE CONFLICT

916 psychologist, sport psychology education should address topics such as organizational

917 dynamics and culture, thus, enabling them to better understand the wider political doings of

918 all involved stakeholders and drive cultural change initiatives if necessary. Lastly, such a

919 position presupposes a sound value system and working philosophy, ethical decision-making

920 and high levels of self-awareness on the part of sport psychology practitioners which may be

921 promoted through regular exchange with or guidance from experienced practitioners who

922 facilitate continuous engagement in reflective practice. With appropriate training, sport

923 psychologists may be more willing, confident and effective in managing interpersonal

924 relationships within sport organizations on every level. 
Running head: THIRD PARTY INTERVENTIONS IN COACH-ATHLETE CONFLICT

926 Andersen, M. B., Van Raalte, J. L., \& Brewer, B. W. (2001). Sport psychology service delivery: Staying ethical while keeping loose. Professional Psychology: Research and Practice, 32(1), 12-18.

Aoyagi, M. W., \& Portenga, S. T. (2010). The role of positive ethics and virtues in the context of sport and performance psychology service delivery. Professional Psychology: Research and Practice, 41(3), 253-259.

Arnold, R., \& Sarkar, M. (2015). Preparing athletes and teams for the Olympic Games: Experiences and lessons learned from the world's best sport psychologists. International Journal of Sport and Exercise Psychology, 13(1), 4-20.

Barki, H., \& Hartwick, J. (2004). Conceptualizing the construct of interpersonal conflict. The International Journal of Conflict Management, 15(3), 216-244.

Becker, A. J. (2009). It's not what they do, it's how they do it: athlete experiences of great coaching. International Journal of Sports Science and Coaching, 4(1), 93-119.

Braun, V., \& Clarke, V. (2019). Reflecting on reflexive thematic analysis. Qualitative Research in Sport, Exercise and Health, 11(4), 589-597.

941 Braun, V., Clarke, V., \& Weate, P. (2016). Using thematic analysis in sport and exercise research. In B. Smith and A. C. Sparkes (Eds.) Routledge handbook of qualitative research in sport and exercise. London: Routledge.

944 Coleman, S. W., \& Prywes, Y. (2014). Teaching conflict resolution skills in a Workshop. In P. T. Coleman, M. Deutsch and E. C. Marcus (Eds) The handbook of conflict resolution: Theory and practice (3rd Ed.). John Wiley \& Sons, Inc.

947 Cook, G. M., \& Fletcher, D. (2017, June 12). Sport psychology in an Olympic swimming team: Perceptions of the management and coaches. Professional Psychology: Research and Practice, 48(5), 343-351. 
Running head: THIRD PARTY INTERVENTIONS IN COACH-ATHLETE CONFLICT

950 Cruickshank, A., Collins, D., \& Minten, S. (2013). Culture change in a professional sports team: Shaping environmental contexts and regulating power. International Journal of Sports Science \& Coaching, 8(2), 271-290.

953

Fisher, R. J. (1972). Third party consultation: A method for the study and resolution of conflict. Journal of Conflict Resolution, 16, 67-94.

955

956

957

958

959

960

961

962

963

964

965

966

967

968

969

970

971

972

973

974 Conflict Transformation. Berghof Research Center for Constructive Conflict Management: Berlin

Fletcher, D., \& Streeter, A. (2016). A case study analysis of a high performance environment in elite swimming. Journal of Change Management, 16(2), 123-141.

Giebels, E., \& Janssen, O. (2005). Conflict stress and reduced well-being at work: The buffering effect of third party help. European Journal of Work and Organizational Psychology, 14(2), 137-155.

Haberl, P., \& Peterson, K. (2006). Olympic-size ethical dilemmas: Issues and challenges for sport psychology consultants on the road and at the Olympic Games. Ethics \& Behavior, 16(1), 25-40.

Holt, N., Knight, C., \& Zukiwski, P. (2012). Female athletes' perceptions of teammate conflict in sport: Implications for sport psychology consultants. The Sport Psychologist, 26, 135-154.

Jowett, S., \& Shanmugam, V. (2016). Relational coaching in sport: Its psychological underpinnings and practical effectiveness. In R. Schinke, K.R. McGannon, B. Smith, Routledge International Handbook of Sport Psychology. Routledge.

Kressel, K. (2014). The mediation of conflict: Context, cognition, and practice. In P. T. Coleman, M. Deutsch and E. C. Marcus (Eds) The handbook of conflict resolution: Theory and practice (3rd Ed.). John Wiley \& Sons, Inc. 
Running head: THIRD PARTY INTERVENTIONS IN COACH-ATHLETE CONFLICT

975 Kressel, K., \& Pruitt, D. G. (1985). Themes in the mediation of social conflict. Journal of Social Issues, 41(2), 179-198.

977 Langan, E., Blake, C., \& Lonsdale, C. (2013). Systematic review of the effectiveness of interpersonal coach education interventions on athlete outcomes. Psychology of Sport and Exercise, 14(1), 37-49.

980

Martin, L. J., Carron, A. V., \& Burke, S. M. (2016). Team building interventions in sport: A meta-analysis. Sport \& Exercise Psychology Review, 5(2), 3-18.

982

McCalla, T., \& Fitzpatrick, S. (2016). Integrating sport psychology within a highperformance team: Potential stakeholders, micropolitics, and culture. Journal of Sport Psychology in Action, 7(1), 33-42.

McCann, S. (2008). At the Olympics, everything is a performance issue. International Journal of Sport and Exercise Psychology, 6(3), 267-276.

McDougall, M., Nesti, M., \& Richardson, D. (2015). The challenges of sport psychology delivery in elite and professional sport: Reflections from experienced sport psychologists. The Sport Psychologist, 29(3), 265-277.

Mellalieu, S., Shearer, D. A., \& Shearer, C. (2013). A preliminary survey of interpersonal 991 conflict at major games and championships. The Sport Psychologist, 27, 120-129.

Paradis, K. F., Carron, A. V, \& Martin, L. J. (2014). Athlete perceptions of intra-group conflict in sport teams. Sport \& Exercise Psychology Review, 10(3), 4-18.

Rhind, D. J., \& Jowett, S. (2012). Working with coach-athlete relationships: Their quality and 995 maintenance. In S. Mellalieu \& S. Hanton (Eds.), Professional Practice in Sport Psychology: A Review (219-248). Routledge

Rowley, C., Potrac, P., Knowles, Z. R., \& Nelson, L. (2018). More than meets the (rationalistic) eye: A neophyte sport psychology practitioner's reflections on the micropolitics of everyday life within a rugby league academy. Journal of Applied $1000 \quad$ Sport Psychology, ahead of print. 
Running head: THIRD PARTY INTERVENTIONS IN COACH-ATHLETE CONFLICT

1001

1002

1003

1004

1005

1006

1007

1008

1009

1010

1011

1012

1013

1014

1015

1016

1017

1018

1019

1020

1021

1022

1023

1024

Smith, B. (2018). Generalizability in qualitative research: Misunderstandings, opportunities and recommendations for the sport and exercise sciences. Qualitative Research in Sport, Exercise and Health, 10, 137-149.

Smith, B., \& Caddick, N. (2012). Qualitative methods in sport: A concise overview for guiding social scientific sport research. Asia Pacific Journal of Sport and Social Science, 1, 60-73.

Smith, B., \& McGannon, K. R. (2017): Developing rigor in qualitative research: Problems and opportunities within sport and exercise psychology. International Review of Sport and Exercise Psychology, 11(1), 101-121.

Vealey, R. S. (2017). Conflict management and cultural reparation: Consulting "Below Zero" with a college basketball team. Case Studies in Sport and Exercise Psychology, 1(1), 83-93.

Wachsmuth, S., Jowett, S., \& Harwood, C. (2017). Conflict among athletes and their coaches: What is the theory and research so far? International Review of Sport and Exercise Psychology, 10(1), 84-107.

Wachsmuth, S., Jowett, S., \& Harwood, C. (2018). Managing conflict in coach-athlete relationships. Sport, Exercise and Performance Psychology, ahead of print.

Wrisberg, C. A., Loberg, L. A., Simpson, D., Withycombe, J. L., \& Reed, A. (2010). An exploratory investigation of NCAA Division-I coaches' support of sport psychology consultants and willingness to seek mental training services. The Sport Psychologist, 24(4), 489-503.

Zakrajsek, R. A., Steinfeldt, J. A., Bodey, K. J., Martin, S. B., \& Zizzi, S. J. (2013). NCAA Division I coaches' perceptions and preferred use of sport psychology services: A qualitative perspective. The Sport Psychologist, 27(3), 258-268. 
Running head: THIRD PARTY INTERVENTIONS IN COACH-ATHLETE CONFLICT

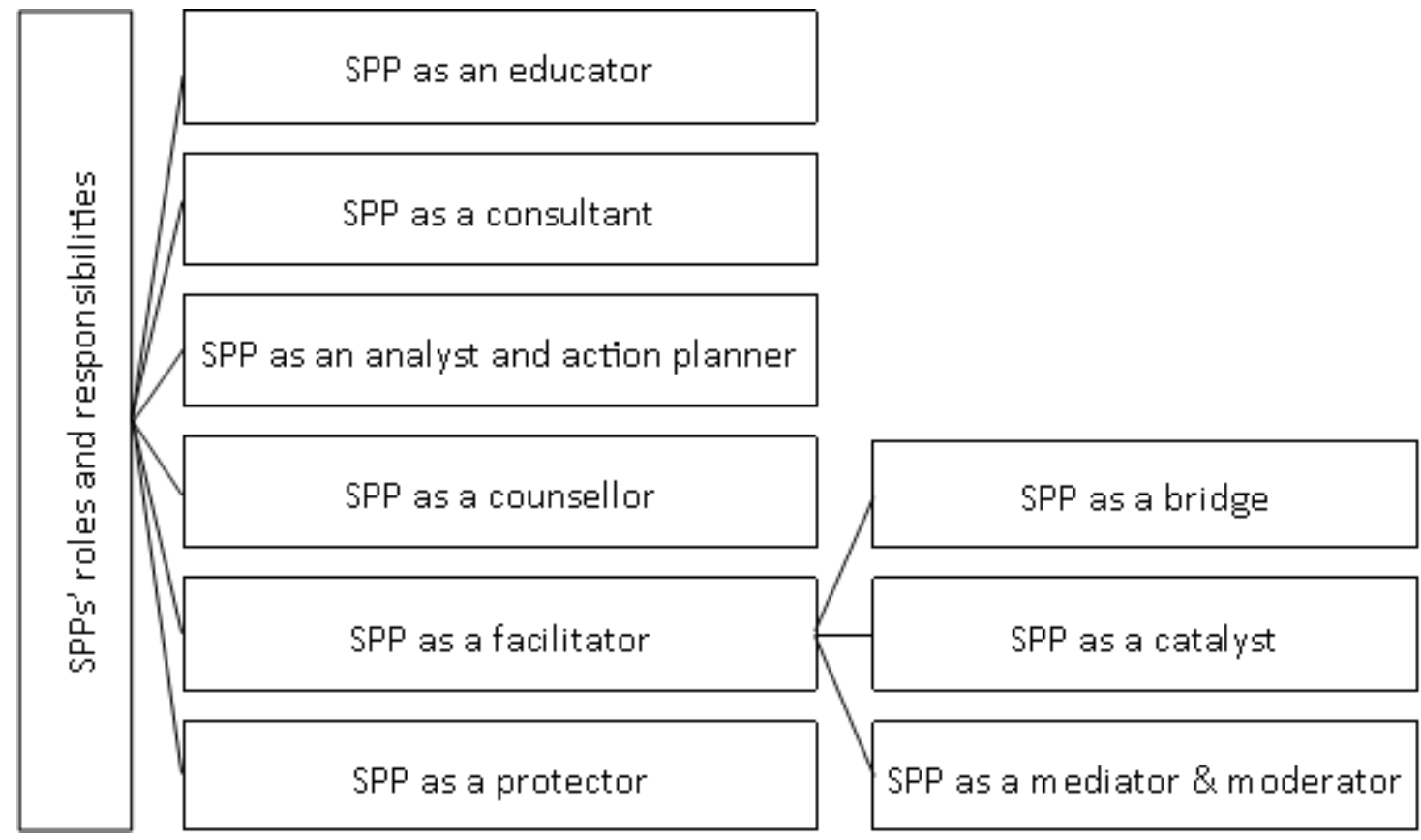

1030 Figure 1. Sport psychology practitioners' perceived roles \& responsibilities.

1031

1032

1033

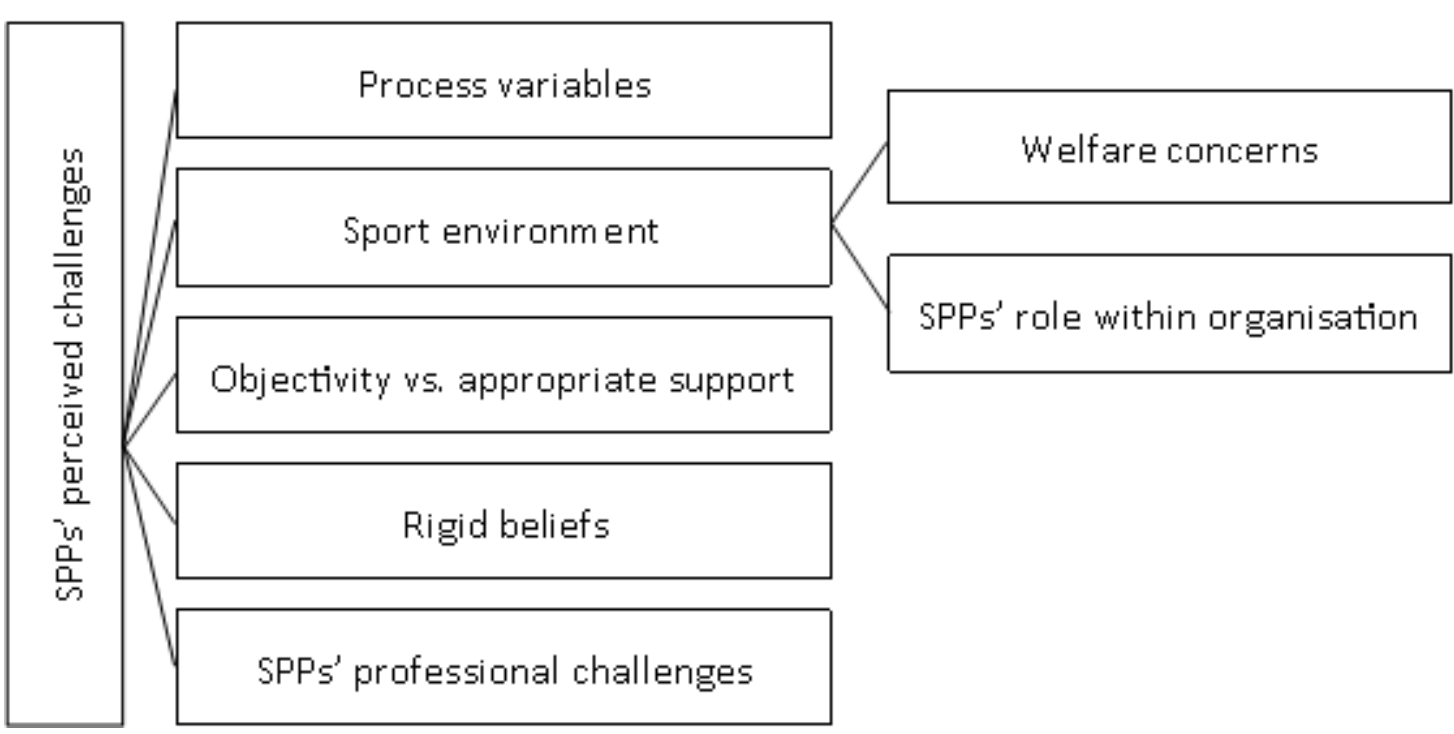

1036 Figure 2. Sport psychology practitioners' perceived challenges in managing coach-athlete conflict. 